\title{
Risk factors for complications after pharyngolaryngectomy with total esophagectomy
}

\author{
Eisuke Booka $^{1,4} \cdot$ Yasuhiro Tsubosa $^{1} \cdot$ Masahiro Niihara $^{1} \cdot$ Wataru Takagi $^{1}$ • \\ Katsushi Takebayashi ${ }^{1}$ - Ayako Shimada ${ }^{1,4}$ - Takashi Kitani ${ }^{2}$ - Masato Nagaoka ${ }^{2}$. \\ Atsushi Imai $^{2} \cdot$ Tomoyuki Kamijo $^{2} \cdot$ Yoshiyuki Iida $^{2} \cdot$ Tetsuro Onitsuka $^{2} \cdot$ \\ Masahiro Nakagawa ${ }^{3} \cdot$ Hiroya Takeuchi $^{4} \cdot$ Yuko Kitagawa $^{4}$
}

Received: 6 February 2016 / Accepted: 15 March 2016 / Published online: 31 March 2016

(C) The Author(s) 2016. This article is published with open access at Springerlink.com

\begin{abstract}
Background Pharyngolaryngectomy with total esophagectomy (PLTE) is an effective surgical treatment for synchronous or metachronous hypopharyngeal or laryngeal cancer and thoracic esophageal cancer, although it is more invasive than esophagectomy and total pharyngolaryngectomy. The aim of this study was to identify risk factors for complications after PLTE.

Methods From November 2002 to December 2014, a total of 8 patients underwent PLTE at the Shizuoka Cancer Center Hospital, Shizuoka, Japan. We investigated the clinicopathological characteristics, surgical procedures, and postoperative complications of these patients.

Results Of the 8 patients, 5 underwent one-stage PLTE and 3 underwent staged PLTE. There was no mortality in this study. Two cases of tracheal necrosis, two of anastomotic leakage, and one of ileus were observed as postoperative complications. Two patients who underwent one-stage PLTE with standard mediastinal lymph node dissection developed tracheal necrosis and severe anastomotic leakage.
\end{abstract}

Yasuhiro Tsubosa

y.tsubosa@scchr.jp

1 Division of Esophageal Surgery, Shizuoka Cancer Center Hospital, 1007 Shimonagakubo, Nagaizumi-cho, Sunto-gun, Shizuoka 411-8777, Japan

2 Division of Head and Neck Surgery, Shizuoka Cancer Center Hospital, 1007 Shimonagakubo, Nagaizumi-cho, Sunto-gun, Shizuoka 411-8777, Japan

3 Division of Plastic and Reconstructive Surgery, Shizuoka Cancer Center Hospital, 1007 Shimonagakubo, Nagaizumi-cho, Sunto-gun, Shizuoka 411-8777, Japan

4 Department of Surgery, Keio University School of Medicine, 35 Shinanomachi, Shinjuku-ku, Tokyo 160-8582, Japan
Conclusion One-stage PLTE and standard mediastinal lymph node dissection were identified as the risk factors for severe postoperative complications. Staged PLTE or transhiatal esophagectomy should be considered when PLTE is performed and standard mediastinal lymph node dissection should be avoided when one-stage PLTE is performed with transthoracic esophagectomy.

Keywords Pharyngolaryngectomy $\cdot$ Total esophagectomy · Tracheal necrosis · Esophageal cancer · Hypopharyngeal cancer

\section{Introduction}

Esophageal cancer is the sixth leading cause of cancerrelated mortality worldwide because of its high malignant potential and poor prognosis [1]. The postoperative 5-year survival rate in patients with American Joint Committee on Cancer stage I esophageal cancer is approximately $90 \%$; it decreases to $45 \%$ in patients with stage II disease, $20 \%$ in those with stage III disease, and $10 \%$ in those with stage IV disease [2]. Although the efficacy of chemoradiotherapy for esophageal cancer has been reported [3], esophagectomy remains the most viable treatment option for esophageal cancer. However, esophagectomy is a highly invasive procedure associated with several serious postoperative complications such as pneumonia, anastomotic leakage, and recurrent laryngeal nerve paralysis, which may result in multiorgan failure [4]. Another clinical problem associated with esophageal cancer is its frequent association with synchronous or metachronous gastric or head and neck cancer [5]. Similar to the difficulty regarding the treatment for gastric tube cancer after esophagectomy previously reported by us [5], it is complicated to treat esophageal cancer with 
synchronous or metachronous head and neck cancer. Pharyngolaryngectomy with total esophagectomy (PLTE) is an effective surgical treatment for synchronous or metachronous hypopharyngeal or laryngeal and thoracic esophageal cancers, although PLTE is more invasive than esophagectomy and total pharyngolaryngectomy (TPL) [6-9].

The fatal complications associated with PLTE are tracheal and gastric tube necrosis caused by insufficient blood flow [10]. PLTE is also indicated for cervicothoracic and cervical esophageal cancers with mediastinal lymph node metastasis [8]. To date, although a few earlier studies have reported the efficacy of PLTE for synchronous or metachronous pharyngeal and thoracic esophageal cancers [6-8], there has been no study investigating the differences between one-stage and staged PLTE. Therefore, this study is the first to draw a comparison between one-stage and staged PLTE. We hypothesized that the chosen surgical procedure for PLTE likely impacts the potential development of postoperative complications. Hence, the aim of this study was to identify potential risk factors for complications after PLTE.

\section{Patients and methods}

\section{Patients}

From November 2002 to December 2014, a total of 375 patients underwent esophagectomy and 140 patients underwent TPL at Shizuoka Cancer Center Hospital, Shizuoka, Japan. In this study, 8 patients who underwent PLTE were retrospectively analyzed. Of these patients, 5 underwent one-stage PLTE and 3 underwent staged PLTE for metachronous pharyngeal and thoracic esophageal cancers. Of the 5 patients who underwent one-stage PLTE, 2 underwent PLTE based on the indication of cervicothoracic esophageal cancer, 2 underwent PLTE based on the indication of synchronous pharyngeal and thoracic esophageal cancers, and 1 underwent PLTE based on the indication of synchronous cervical and thoracic esophageal cancers. Of the 3 patients who underwent staged PLTE for metachronous pharyngeal and thoracic esophageal cancers, 2 underwent TPL followed by esophagectomy and 1 underwent esophagectomy followed by TPL. Clinical staging of esophageal and pharyngeal cancers was categorized according to the International Union Against Cancer (UICC) 7th edition tumor-node-metastasis (TNM) classification [11].

\section{Preoperative treatment}

Of the 8 patients who underwent PLTE, 7 received preoperative treatment of definitive chemoradiotherapy (dCRT) (5 patients) or neoadjuvant chemotherapy (2 patients). Definitive chemoradiotherapy comprised the concurrent administration of approximately 60 Gy radiation with 5-fluorouracil and cisplatin. Salvage surgery was indicated for residual or recurrent lesions after dCRT. Neoadjuvant chemotherapy comprised 5-fluorouracil and cisplatin.

\section{Surgical procedure}

Esophagectomy was performed through right thoracotomy, video-assisted thoracic surgery (VATS), or transhiatal procedures by esophageal surgeons. Esophagectomy through right thoracotomy or VATS included standard mediastinal lymph node dissection. However, the dissection was avoided when salvage surgery was performed considering the high risk of complications associated with the surgery. TPL was performed by esophageal or head and neck surgeons according to the tumor location. In this study, the reconstructed organ was the stomach in all cases. Pharyngogastric anastomosis was performed by esophageal surgeons when the whole stomach or pulled-up gastric tube could reach the hypopharynx. When the gastric tube had been pulled up but could not reach the hypopharynx, free jejunal transfer (FJT) with microvascular anastomosis was performed to repair the cervical defect between the hypopharynx and the oral side of the gastric tube by plastic and reconstructive surgeons. Two anastomoses were required in this case: pharyngojejunal and jejunal gastric. Postoperative complications were categorized using the Clavien-Dindo (CD) classification [12, 13].

\section{Results}

\section{Patient and clinicopathological characteristics}

The clinicopathological characteristics of patients who underwent one-stage PLTE and staged PLTE are summarized in Tables 1 and 2, respectively. The median age at the time of PLTE and first staged PLTE was 63.5 years (range 43-69 years). The study cohort of 8 patients comprised 6 males and 2 females. Standard mediastinal lymph node dissection was performed in all patients of staged PLTE (patients 6, 7, and 8) and 2 patients of one-stage PLTE (patients 4 and 5), whereas standard mediastinal lymph node dissection was avoided in all patients of salvage surgery (patients 1,2, and 3).

Patients 1 and 2 underwent dCRT and salvage PLTE for residual lesions. Patient 3 underwent dCRT for pharyngeal cancer, which resulted in a complete response. However, pharyngeal cancer recurrence after dCRT and synchronous esophageal cancer was observed in 2 lesions, which were subsequently treated by PLTE. Patients 4 and 5 underwent PLTE for synchronous double cancers. 
Table 1 Clinicopathological characteristics of patients who underwent one-stage PLTE

\begin{tabular}{|c|c|c|c|c|c|c|c|c|c|}
\hline Patient & $\begin{array}{l}\text { Age } \\
\text { (years) }\end{array}$ & Sex & Cancer Site & $\begin{array}{l}\text { cTNM } \\
\text { (UICC 7th) }\end{array}$ & $\begin{array}{l}\text { Preoperative } \\
\text { treatment }\end{array}$ & $\begin{array}{l}\text { Method of } \\
\text { esophagec- } \\
\text { tomy }\end{array}$ & $\begin{array}{l}\text { Standard } \\
\text { mediastinal } \\
\text { lymph node } \\
\text { dissection }\end{array}$ & $\begin{array}{l}\text { Reconstructed } \\
\text { method }\end{array}$ & $\begin{array}{l}\text { Reconstructed } \\
\text { route }\end{array}$ \\
\hline 1 & 64 & Male & $\mathrm{Ce}$ & T4bN1M0 & $\begin{array}{l}\text { dCRT } \\
(2 \text { months } \\
\text { after radia- } \\
\text { tion) }\end{array}$ & Transhiatal & No & $\begin{array}{l}\text { Whole stom- } \\
\text { ach }\end{array}$ & $\begin{array}{l}\text { Posterior medi } \\
\text { astinal }\end{array}$ \\
\hline 2 & 69 & Male & $\mathrm{UtCe}$ & T2N1M0 & $\begin{array}{l}\text { dCRT } \\
(2 \text { months } \\
\text { after radia- } \\
\text { tion) }\end{array}$ & Transhiatal & No & $\begin{array}{l}\text { Gastric } \\
\text { tube }+ \text { FJT }\end{array}$ & $\begin{array}{l}\text { Posterior medi- } \\
\text { astinal }\end{array}$ \\
\hline 3 & 66 & Male & $\mathrm{Ph}$ & T2N0M0 & $\begin{array}{l}\text { dCRT } \\
\quad(52 \text { months } \\
\text { after radia- } \\
\text { tion) }\end{array}$ & Transthoracic & No & $\begin{array}{l}\text { Gastric } \\
\text { tube }+ \text { FJT }\end{array}$ & $\begin{array}{l}\text { Posterior medi } \\
\text { astinal }\end{array}$ \\
\hline 4 & 57 & Female & $\begin{array}{l}\mathrm{Mt} \\
\mathrm{Ce}\end{array}$ & $\begin{array}{l}\text { T1aN1M0 } \\
\text { T3N0M0 }\end{array}$ & NeoFP & Transthoracic & Yes & $\begin{array}{l}\text { Gastric } \\
\text { tube }+ \text { FJT }\end{array}$ & $\begin{array}{l}\text { Posterior medi- } \\
\text { astinal }\end{array}$ \\
\hline 5 & 63 & Male & $\begin{array}{l}\mathrm{Mt} \\
\mathrm{Ph} \\
\mathrm{Mt}\end{array}$ & $\begin{array}{l}\text { T1N0M0 } \\
\text { T4aN2bM0 } \\
\text { T1bN1M0 }\end{array}$ & & VATS & Yes & $\begin{array}{l}\text { Gastric } \\
\text { tube }+ \text { FJT }\end{array}$ & $\begin{array}{l}\text { Posterior medi- } \\
\text { astinal }\end{array}$ \\
\hline
\end{tabular}

PLTE Pharyngolaryngectomy with total esophagectomy, $c T N M$ clinical tumor-node-metastasis, UICC international union against cancer, $P h$ pharynx, $C e$ cervical esophagus, $U t$ upper thoracic esophagus, $M t$ middle thoracic esophagus, $d C R T$ definitive chemoradiotherapy, NeoFP neoadjuvant chemotherapy comprised 5-fluorouracil and cisplatin, VATS video-assisted thoracic surgery, FJT free jejunal transfer

Table 2 Clinicopathological characteristics of patients who underwent staged PLTE

\begin{tabular}{|c|c|c|c|c|c|c|c|c|c|c|c|}
\hline Patient & $\begin{array}{l}\text { Age } \\
\text { (years) }\end{array}$ & Sex & $\begin{array}{l}\text { First site } \\
\text { of cancer }\end{array}$ & $\begin{array}{l}\text { cTNM } \\
\text { (UICC 7th) }\end{array}$ & $\begin{array}{l}\text { Preoperative } \\
\text { treatment }\end{array}$ & $\begin{array}{l}\text { First opera- } \\
\text { tion }\end{array}$ & $\begin{array}{l}\text { Duration } \\
\text { (months) }\end{array}$ & $\begin{array}{l}\text { Second } \\
\text { site of } \\
\text { cancer }\end{array}$ & $\begin{array}{l}\text { cTNM } \\
\text { (UICC } \\
7 \text { th) }\end{array}$ & $\begin{array}{l}\text { Preopera- } \\
\text { tive treat- } \\
\text { ment }\end{array}$ & $\begin{array}{l}\text { Second } \\
\text { operation }\end{array}$ \\
\hline 6 & 43 & Female & $\mathrm{Ph}$ & $\mathrm{T} 4 \mathrm{aN} 2 \mathrm{bM} 0$ & & $\mathrm{TPL}+\mathrm{FJT}$ & 25 & $\mathrm{Lt}$ & T1bN1M0 & NeoFP & $\begin{array}{l}\text { TTE + pos- } \\
\text { terior } \\
\text { mediasti- } \\
\text { nal gastric } \\
\text { tube }\end{array}$ \\
\hline 7 & 64 & Male & $\mathrm{Ce}$ & T4bN0M0 & $\begin{array}{l}\text { dCRT } \\
\text { (36 months } \\
\text { after radia- } \\
\text { tion) }\end{array}$ & $\mathrm{TPL}+\mathrm{FJT}$ & 1 & Mt & T1bN0M0 & & $\begin{array}{l}\text { TTE + pos- } \\
\text { terior } \\
\text { mediasti- } \\
\text { nal gastric } \\
\text { tube }\end{array}$ \\
\hline 8 & 57 & Male & MtUtLt & T4bN1M0 & $\begin{array}{l}\text { dCRT } \\
\text { (3 months } \\
\text { after radia- } \\
\text { tion) }\end{array}$ & $\begin{array}{l}\text { TTE + ret- } \\
\text { rosternal } \\
\text { gastric } \\
\text { tube }\end{array}$ & 23 & $\mathrm{Ph}$ & $\mathrm{T} 3 \mathrm{~N} 2 \mathrm{cM} 0$ & & $\mathrm{TPL}+\mathrm{FJT}$ \\
\hline
\end{tabular}

PLTE Pharyngolaryngectomy with total esophagectomy, $c T N M$ clinical tumor-node-metastasis, UICC international union against cancer, Duration duration between operations (months), $P h$ pharynx, $C e$ cervical esophagus, $U t$ upper thoracic esophagus, $M t$ middle thoracic esophagus, $L t$ lower thoracic esophagus, $d C R T$ definitive chemoradiotherapy, NeoFP neoadjuvant chemotherapy comprised 5-fluorouracil and cisplatin, $T P L$ total pharyngolaryngectomy, $F J T$ free jejunal transfer, TTE transthoracic esophagectomy

Patient 6 underwent TPL with FJT as the first surgery. However, 25 months later, this patient underwent esophagectomy with posterior mediastinal gastric tube reconstruction. Patient 7 underwent salvage TPL with FJT for severe stenosis after dCRT followed 1 month later by esophagectomy with posterior mediastinal gastric tube reconstruction as the second operation. Patient 8 underwent salvage esophagectomy with retrosternal gastric tube reconstruction for residual lesions after dCRT. Twentythree months after salvage esophagectomy, this patient underwent TPL with FJT for metachronous pharyngeal cancer. A second operation was performed for palliative care, and a portion of the cervical esophagus was preserved with minimum invasiveness. 
Table 3 Clinical outcome after PLTE for all 8 patients

\begin{tabular}{|c|c|c|c|c|c|}
\hline Patient & Surgical duration (min) & Blood loss (ml) & Complications (CD classification) & Hospital stay (day) & Outcome \\
\hline 1 & 443 & 1430 & & 30 & $\begin{array}{l}\text { Dead at } 14 \text { months (lung metas- } \\
\text { tasis) }\end{array}$ \\
\hline 2 & 730 & 1002 & Anastomotic leakage (II) & 27 & Alive at 38 months \\
\hline 3 & 415 & 580 & & 25 & Alive at 37 months \\
\hline 4 & 536 & 183 & Tracheal necrosis (IIIa) & 25 & Alive at 23 months \\
\hline 5 & 724 & 384 & $\begin{array}{l}\text { Anastomotic leakage (IIIb), } \\
\text { tracheal necrosis (IIIa) }\end{array}$ & 99 & Alive at 12 months \\
\hline 6 & 414 & 631 & & 18 & Alive at 89 months \\
\hline 7 & 587 & 735 & Ileus (IIIb) & 45 & Dead at 53 months (pneumonia) \\
\hline 8 & 702 & 179 & & 32 & $\begin{array}{l}\text { Alive at } 7 \text { months (lymph node } \\
\text { metastasis) }\end{array}$ \\
\hline
\end{tabular}

PLTE Pharyngolaryngectomy with total esophagectomy, CD Clavien-Dindo

\section{Clinical outcome after PLTE}

The clinical outcomes after PLTE for all 8 patients are shown in Table 3. For the patients who underwent staged PLTE (patients 6, 7, and 8), there were no postoperative complications from the first operation. The perioperative and postoperative outcomes of the second operation are shown in Table 3.

The mean operation time was 569 min (range 443$730 \mathrm{~min}$ ) and the median blood loss was $640 \mathrm{ml}$ (range $179-1430 \mathrm{ml})$. The median hospital stay was 28.5 days (range 18-99 days). There was no instance of mortality in this study. Two cases of tracheal necrosis (patients 4 and 5), 2 of anastomotic leakage (patients 2 and 5), and 1 of ileus (patient 7) were observed as postoperative complications.

The occurrence of tracheal necrosis is shown in Fig. 1 (patients 4 and 5). In case of patient 4 , tracheal necrosis was observed on postoperative day (POD) 9 (Fig. 1a) and a tracheostomy tube was inserted against tracheal stenosis on POD 79. Tracheal necrosis improved on POD 164 (Fig. 1b). In case of patient 5, tracheal necrosis was observed on POD 13 (Fig. 1c) and a tracheostomy tube was inserted against tracheal stenosis on POD 16. The membranous portion of the trachea was melted on POD 26 and fistula formation was observed on POD 40. Fistula closure was performed on POD 77 and tracheal necrosis improved on POD 113 (Fig. 1d).

Patient 1 died because of lung metastasis at 14 months and patient 7 died because of pneumonia that were not related to esophageal cancer at 53 months. The remaining 6 patients are alive, including 1 who experienced lymph node recurrence (patient 8 ) and 5 who experienced no recurrence.

\section{Discussion}

PLTE is an effective surgical treatment for synchronous or metachronous hypopharyngeal or laryngeal and thoracic esophageal cancers. However, PLTE is more invasive than esophagectomy or TPL, and it is important to prevent postoperative complications and consider indications for this invasive procedure $[6-8,14]$.

At our institution, the eligibility criteria for PLTE were not clearly defined. However, we decided the criteria after careful consideration of all the factors that would comprehensively affect patient life. As a result, the average age of participants in this study cohort was less than usual cohort of esophageal cancer [15].

In this study, tracheal necrosis developed in patients 4 and 5 and severe anastomotic leakage developed in patient 5 , and the severe anastomotic leakage was believed to stem from tracheal necrosis. Subsequently, these patients underwent transthoracic or thoracoscopic esophagectomy with standard mediastinal lymph node dissection, and it was possible that insufficient tracheal blood flow developed in response to standard mediastinal lymph node dissection [16]. Tracheal necrosis is considered to develop in response to insufficient tracheal blood flow $[10,16]$. Patient 3 underwent transthoracic esophagectomy; however, standard mediastinal lymph node dissection was avoided considering the high risk associated with salvage surgery [17]; therefore, tracheal blood flow was preserved. For the 2 patients (patients 1 and 2) who underwent transhiatal esophagectomy, tracheal blood flow was preserved because mediastinal lymph node dissection was not performed. For the 3 patients (patients 6,7 , and 8) who underwent staged PLTE, transthoracic esophagectomy with standard mediastinal lymph node dissection was performed. However, tracheal blood flow bypass was thought to have been created 
Fig. 1 a, b Tracheal necrosis on postoperative day (POD) 9 (a) and improvement on POD 164 (b) in case 4. c, $\mathbf{d}$ Tracheal necrosis on postoperative day (POD) 13 (c) and improvement on POD $113(\mathbf{d})$ in case 5

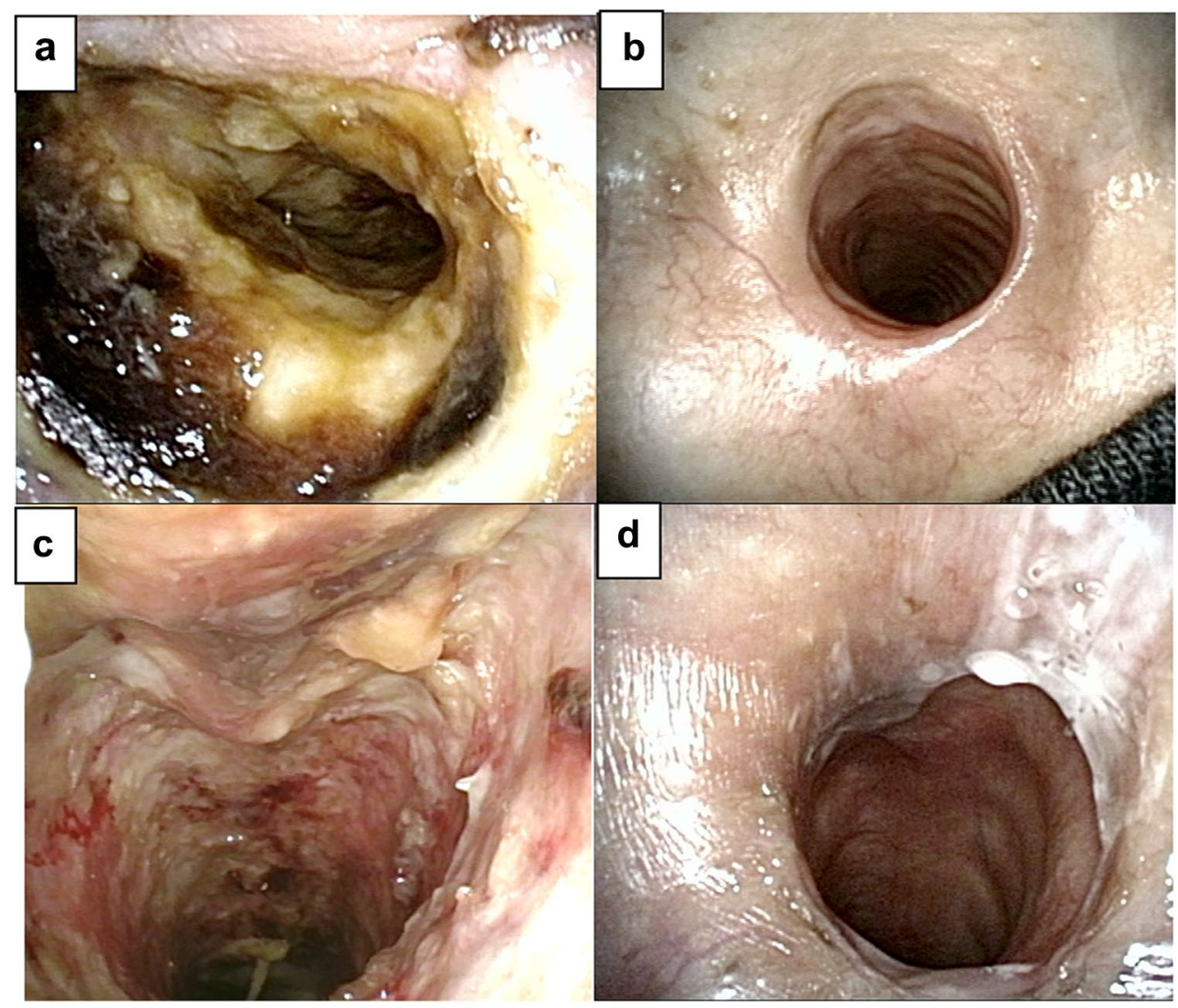

in response. One-stage PLTE and standard mediastinal lymph node dissection were identified as risk factors of severe postoperative complications, particularly tracheal necrosis.

Staged PLTE was performed for metachronous cancers but not planed as the first operation in this study. In the second operation, when the staged PLTE required efforts and cervical esophagus could not be resected in cases such as patient 8, staged PLTE may have contributed to the occurrence of tracheal blood flow bypass and was considered to be an effective procedure. Moreover, some reports have claimed that staged PLTE is safe and effective for high-risk patients [7, 8]. In this study, the shortest duration between the first and second procedures was 1 month, and tracheal blood flow bypass can occur within this period. Nonetheless, our experience indicates that staged PLTE could be effective and safe for both metachronous and synchronous cancers.

Definitive CRT tends to be the initial treatment for synchronous double head and neck and thoracic esophageal cancers [7]. However, some salvage treatment is required in cases with either residual or recurrent disease after dCRT [7]. It is considered that salvage surgery after dCRT is a high-risk factor for severe postoperative complications [9, 17]. In this study, 5 patients $(62.5 \%)$ underwent salvage
PLTE after dCRT, which resulted in no instance of tracheal necrosis or severe anastomotic leakage. Therefore, we propose that salvage surgery can be safely performed when staged PLTE or transhiatal esophagectomy is selected.

In this study, those 2 patients who developed tracheal necrosis developed tracheal stenosis when tracheal necrosis improved. In these 2 patients, insertion of a tracheostomy tube was effective to improve tracheal stenosis. In cases in which tracheal stenosis cannot be avoided when tracheal necrosis improves, a tracheostomy tube should be inserted to treat tracheal stenosis [18].

In conclusion, one-stage PLTE and standard mediastinal lymph node dissection were identified as risk factors for severe postoperative complications. Staged PLTE or transhiatal esophagectomy should be considered when PLTE is performed and standard mediastinal lymph node dissection should be avoided when one-stage PLTE is performed with transthoracic esophagectomy.

\section{Compliance with ethical standards}

Ethical Statement All procedures followed were in accordance with the approval of the Ethics Committee of Shizuoka Cancer Center Hospital and Helsinki Declaration of 1964 and later versions. Informed consent or substitute for it was obtained from all patients for being included in the study. 
Conflict of interest The authors declare that they have no conflicts of interest associated with this study.

Open Access This article is distributed under the terms of the Creative Commons Attribution 4.0 International License (http://creativecommons.org/licenses/by/4.0/), which permits unrestricted use, distribution, and reproduction in any medium, provided you give appropriate credit to the original author(s) and the source, provide a link to the Creative Commons license, and indicate if changes were made.

\section{References}

1. Jemal A, Bray F, Center MM, et al. Global cancer statistics. CA Cancer J Clin. 2011;61:69-90.

2. Ando N, Ozawa S, Kitagawa Y, et al. Improvement in the results of surgical treatment of advanced squamous esophageal carcinoma during 15 consecutive years. Ann Surg. 2000;232:225-32.

3. Cooper JS, Guo MD, Herskovic A, et al. Chemoradiotherapy of locally advanced esophageal cancer: long-term follow-up of a prospective randomized trial (RTOG 85-01). Radiation therapy oncology group. JAMA. 1999;281:1623-7.

4. Booka E, Takeuchi H, Nishi T, et al. The impact of postoperative complications on survivals after esophagectomy for esophageal cancer. Medicine (Baltimore). 2015;94:e1369.

5. Booka E, Takeuchi H, Okamoto N, et al. Gastric tube cancer after radical esophagectomy: comparison of two periods in a single center. Esophagus. 2015;13:55-61.

6. Ida S, Morita M, Hiyoshi Y, et al. Surgical resection of hypopharynx and cervical esophageal cancer with a history of esophagectomy for thoracic esophageal cancer. Ann Surg Oncol. 2014;21:1175-81.

7. Morita M, Kawano H, Otsu $\mathrm{H}$, et al. Surgical resection for esophageal cancer synchronously or metachronously associated with head and neck cancer. Ann Surg Oncol. 2013;20:2434-9.
8. Morita M, Saeki H, Ito S, et al. Technical improvement of total pharyngo-laryngo-esophagectomy for esophageal cancer and head and neck cancer. Ann Surg Oncol. 2014;21:1671-7.

9. Elias D, Cavalcanti A, Dube P, et al. Circumferential pharyngolaryngectomy with total esophagectomy for locally advanced carcinomas. Ann Surg Oncol. 1998;5:511-6.

10. Watanabe M, Baba Y, Yoshida N, et al. Modified gastric pullup reconstructions following pharyngolaryngectomy with total esophagectomy. Dis Esophagus. 2014;27:255-61.

11. Sobin LGM, Wittekind C. TNM classification of malignant tumors. New York: Wiley-Blackwell; 2009.

12. Clavien PA, Barkun J, de Oliveira ML, et al. The Clavien-Dindo classification of surgical complications: five-year experience. Ann Surg. 2009;250:187-96.

13. Dindo D, Demartines N, Clavien PA. Classification of surgical complications: a new proposal with evaluation in a cohort of 6336 patients and results of a survey. Ann Surg. 2004;240:205-13.

14. Kamiyama R, Mitani H, Yonekawa H, et al. A clinical study of pharyngolaryngectomy with total esophagectomy: postoperative complications, countermeasures, and prognoses. Otolaryngol Head Neck Surg. 2015;153:392-9.

15. Tachimori Y, Ozawa S, Fujishiro M, et al. Comprehensive registry of esophageal cancer in Japan, 2006. Esophagus. 2013;11:21-47.

16. Fujiki M, Miyamoto S, Sakuraba M, et al. Risk factors for tracheal necrosis after total pharyngolaryngectomy. Head Neck. 2015;37:1207-10.

17. Niwa Y, Koike M, Fujimoto Y, et al. Salvage pharyngolaryngectomy with total esophagectomy following definitive chemoradiotherapy. Dis Esophagus. 2015. doi:10.1111/dote.12362.

18. Homma A, Nakamaru Y, Hatakeyama H, et al. Early and longterm morbidity after minimally invasive total laryngo-pharyngo-esophagectomy with gastric pull-up reconstruction via thoracoscopy, laparoscopy and cervical incision. Eur Arch Otorhinolaryngol. 2015;272:3551-6. 